\title{
Harmless bodily pleasures are moralized because they are perceived as reducing self-control and cooperativeness
}

\author{
Léo Fitouchi ${ }^{1}$, Jean-Baptiste André ${ }^{1}$ Nicolas Baumard ${ }^{1} \&$ Daniel Nettle $^{2}$ \\ ${ }^{1}$ Institut Jean Nicod, Département d'Études cognitives, ENS, EHESS, PSL University, \\ CNRS, Paris, France \\ ${ }^{2}$ Population Health Sciences Institute, Newcastle University
}

\begin{abstract}
Why do some people moralize overindulgence in inherently victimless bodily pleasures, such as gluttony, masturbation, drinking, or laziness, when these behaviors appear devoid of any harmful consequences to other people? According to the Moral Disciplining Theory of puritanism, these moral judgements stem from perceptions that bodily pleasures indirectly facilitate antisocial behaviors by altering self-control. In two online experiments on American adults $(N>1,100)$, we find that participants judged that targets who were caused to increase their indulgence in sex, food, alcohol, and laziness, would reduce their self-control and become more likely to cheat in cooperative interactions. Participants judged, by contrast, that sustained restraint from bodily pleasures would improve targets' self-control and cooperativeness. The effect of indulgence (vs. restraint) on perceived change in cooperativeness was fully mediated by perceived change in self-control. Finally, the more people perceived indulgence as reducing self-control and cooperativeness, the more they regarded indulgence in victimless bodily pleasures as morally wrong. These results support the idea that, while often assumed to be independent of concerns for harm or fairness, moralizations of purity stem from cooperation-related inferences-in line with cooperationbased theories of moral cognition.
\end{abstract}

Keywords: cooperation, morality, moral character, puritanism, purity, self-control, sin, temptation 


\section{Introduction}

In many societies, people moralize immoderate indulgence in seemingly victimless bodily pleasures, such as food, sex, alcohol, gambling, or laziness; and regard restraint, temperance, and self-discipline as fundamental moral virtues (Dabhoiwala, 2012; Glucklich, 2020; Haidt, 2012; Haidt \& Graham, 2007). Such puritanical values are found across the most widespread world religions, from Christian morality (e.g., the "deadly sins" of gluttony, lust, and sloth; Le Goff, 1984; Newhauser \& Ridyard, 2012; Sweeney, 2012) to Hinduism (Doniger, 2014), Buddhism (Sterckx, 2005), Islam (Garden, 2014; Mernissi, 2011; Michalak \& Trocki, 2006), Chinese religions (Nylan, 2011; Yü, 2021) and Ancient Greco-Roman spiritualities (Gaca, 2003; Langlands, 2006).

Converging with this historical recurrence, psychological and survey data reveal that a substantial part of the world's population moralizes excessive eating (Mooijman et al., 2018; Ringel \& Ditto, 2019), masturbation (Haidt et al., 1993; Helzer \& Pizarro, 2011), casual sex (Horberg et al., 2009; Weeden \& Kurzban, 2013, 2016), alcohol use (Najjar et al., 2016; Poushter, 2014), gambling (Lugo et al., 2013; Poushter, 2014) intemperance (Mooijman et al., 2018), hedonism (Saroglou et al., 2004; Saroglou \& Craninx, 2021), and reluctance to needless work (Celniker et al., 2020; Tierney et al., 2021). Why do people, across many societies and historical periods, develop this constellation of puritanical values?

The question is all the more puzzling that, as opposed to most other moral norms such as fairness, reciprocity, or loyalty, puritanical values condemn behaviors apparently devoid of any harmful consequences to other people (Haidt \& Graham, 2007). They moralize failure to restrain impulses for food pleasure even when this doesn't amount to failing in one's duty to share, or to respect others' property (Hill, 2007, 2011; Mooijman et al., 2018). They condemn immoderate indulgence in sexual pleasure even when the latter is neither adulterous nor socially harmful, such as in masturbation, or lustful sexuality within marriage (Dabhoiwala, 2012; Haidt et al., 1993; Haidt \& Hersh, 2001; Seidman, 1990). They condemn alcohol and drug use even in private, non-social contexts (Goode \& BenYehuda, 2010; Levine, 1993; Michalak \& Trocki, 2006); and value self-discipline and industriousness even when work would be needless and effort unproductive (Celniker et al., 2020; Tierney et al., 2021).

These "harmless wrongs," thus, are often regarded as critical blind spots of cooperation-based theories of morality, which regard morality as a cognitive adaptation to the challenges of cooperation recurrent in human social life (Alexander, 1987; André et al., 2022; Baumard et al., 2013; Curry, 2016; Stanford, 2018; Tomasello, 2016). Explaining the full breadth of the moral domain, researchers argue, requires (i) recognizing that "there is more to morality than harm and fairness" (Haidt, 2012), and (ii) adopting "pluralist" theories of the moral mind that make room for mechanisms generating moral intuitions without functioning for cooperation (Graham et al., 2013; Haidt, 2012; Haidt \& Joseph, 2007; see also Beal, 2020).

Moral Foundations Theory, in particular, proposes that disgust - an emotion evolved for the non-social challenge of pathogen avoidance-explains moral concerns of 
"Purity/Sanctity", analogous to those we here labelled "puritanical values" (Graham et al., 2013; Haidt, 2012; Haidt \& Joseph, 2007). Giving in to "base impulses", such as gluttony, lust, or intemperance, would be moralized because it elicits disgust in face of behaviors perceived as threatening "spiritual purity" (Haidt \& Graham, 2007). Proponents of this hypothesis point to abundant research finding associations between moralizations of purity and feelings of disgust (Haidt et al., 1993; Haidt \& Hersh, 2001; Rozin et al., 1999), disgustsensitivity (e.g., Crawford et al., 2014; Horberg et al., 2009; Inbar et al., 2009; Wagemans et al., 2018), or experimentally induced disgust (Horberg et al., 2009; Inbar et al., 2012). The ability of disgust to generate moral judgements, however, is increasingly disputed (Inbar \& Pizarro, 2021; Kayyal et al., 2015; Piazza et al., 2018; see also Cameron et al., 2015), as correlations between disgust-sensitivity and purity moralizations disappear when perceptions of harm are controlled for (Gray \& Schein, 2016; Schein et al., 2016), and meta-analytic evidence (Landy \& Goodwin, 2015), highly powered replications (Ghelfi et al., 2020; Johnson et al., 2016), and recent studies (Jylkkä et al., 2021) strongly suggest that feelings of disgust do not increase moral condemnation, nor cause moralization of otherwise morally neutral actions.

Contesting the disgust hypothesis, many researchers have argued that apparently harmless wrongs are, despite appearances, reducible to concerns for harm and fairness (Fitouchi et al., 2021a; Gray et al., 2014; Gray \& Schein, 2016; Royzman et al., 2014; Royzman et al., 2009, 2015; Schein \& Gray, 2018). Focusing on puritanical moralizations, the Moral Disciplining Theory of puritanism proposes that overindulgence in bodily pleasures is condemned because they are perceived as indirectly facilitating uncooperative behavior by altering people's self-control (Fitouchi et al., 2021c; see also 2021b).

Psychological evidence indeed shows that people perceive self-control as necessary for cooperative behavior, expect individuals with lower self-control to behave less cooperatively, and grant more trust to individuals perceived as more self-controlled (Buyukcan-Tetik et al., 2015; Buyukcan-Tetik \& Pronk, 2021; Peetz \& Kammrath, 2013; Righetti \& Finkenauer, 2011). The intuition that self-control is necessary for cooperation appears somewhat justified, as cooperative behaviors often require renouncing the immediate rewards of cheating (e.g., immediate access to resources, sex, rest), this short-term cost being only repaid in the future by the benefits of others' reciprocations and a trustworthy reputation (Axelrod, 2006; LiePanis \& André, 2021; Manrique et al., 2021; Roberts, 2020; Stevens et al., 2005; Stevens \& Hauser, 2004). Accordingly, psychological evidence shows that cooperative behavior depends on people's ability to resist temptations of immediate rewards (resisting the "temptation to cheat"; Hofmann et al., 2018; Knoch et al., 2009; Sjåstad, 2019; Vonasch \& Sjåstad, 2021), and that self-controlled individuals are less prone to behaving uncooperatively in a wide range of ways (e.g., stinginess, adultery, free-riding, aggression; Burnette et al., 2014; Cohen et al., 2014; Fan et al., 2020; Fehr \& Leibbrandt, 2011; Moffitt et al., 2011; Schmitt, 2004; Sebastián-Enesco \& Warneken, 2015; Sjåstad, 2019; Vazsonyi et al., 2017),

People may also perceive that repeated indulgence in bodily pleasures reduces selfcontrol, and, symmetrically, that regular practice of restraint and moderation improves selfcontrol. Field experiments on parents suggest a widespread belief that children's self-control 
can be improved, associated with training practices, such as giving children unhealthy snacks less often, or bringing them less frequently to fast-food restaurants (Mukhopadhyay \& Yeung, 2010). Survey data suggest that a substantial share of people believe that high-fat, high-sugar foods, drugs, and pornography can be addictive (Bradley et al., 2016; Droubay \& Butters, 2020; Edelstein et al., 2020; Grubbs et al., 2018; Ruddock \& Hardman, 2017), and may thus disrupt people's self-control (Vonasch et al., 2017). This converges with historical and ethnographic observations that puritanical cultures describe bodily pleasures as dangerously addictive, and self-control as a virtue that can be maintained only through sustained restraint, daily self-discipline, and consistent training of temperance (e.g., Victorian England: Seidman, 1990; world religions: Glucklich, 2020; Medieval Christianity: Dabhoiwala, 2012; Hinduism: Doniger, 2014; North India: Vatuk \& Vatuk, 1967; Early China: Nylan, 2001; Ancient Greco-Roman wisdoms: Gaca, 2003; Zanzibar: Beckmann, 2010; Amhara, Ethiopia: Levine, 1965).

If people perceive both that self-control is necessary for cooperative behavior (Righetti \& Finkenauer, 2011), and that overindulgence in bodily pleasures reduces self-control, they may moralize bodily pleasures as indirectly facilitating antisocial behaviors (Fitouchi et al., 2021c).

Here, we test several predictions of this general hypothesis. We investigate whether overindulgence in bodily pleasures is perceived as reducing people's self-control, and hence their cooperativeness and moral character. In two studies, participants judged whether a target recently led to increase his consumption of bodily pleasures had become, as a result of this lifestyle change, more likely to commit uncooperative behaviors, compared to a target led to practice restraint and moderation over a period of three months. We tested whether the effect of indulgence (vs. restraint) on perceived change in cooperativeness was associated with, and mediated by, the perceived effect of indulgence (vs. restraint) on self-control-in line with the idea that people perceive indulgence as facilitating uncooperative behaviors because of indulgence's deleterious effect on self-control. We also predicted that the more people perceive indulgence (or restraint) as reducing (or increasing) self-control and cooperativeness, the more they would judge harmless bodily pleasures to be morally wrong.

\section{Study 1}

\section{Methods}

Pre-registration. Design and predictions for this study were pre-registered prior to data collection. Pre-registration, study materials, data, and analysis scripts are available at https://osf.io/52thu/. Numbered predictions in the Results section (e.g. P1) refer to the preregistration document.

Participants. 401 American participants (199 males, 198 females, 4 unknown; $M_{\text {age }}=33.22$, $\left.S D_{\text {age }}=12.54\right)$ were recruited from online research participation platform www.prolific.co. Our pre-registered sample size was determined by a priori power analysis using $G^{*}$ Power 3, based on a minimal effect size of interest of $d=0.3$ for our main experimental effects, which 
is conventionally considered a small-to-medium effect size (Cohen, 1988). 400 participants provide more than $80 \%$ power ( $\alpha=0.05$, two-sided t-tests) for testing our experimental predictions. Twenty-two participants who failed the attention check were excluded from the sample, bringing sample size to 379 .

Procedure. The study used a between-subjects design. After consenting, participants were randomly assigned to one of 2 conditions (Restraint or Indulgence). In the Restraint condition, participants read a vignette about a target led to decrease his consumption of bodily pleasures in the last three months:

Three months ago, Max won a free discovery pack to participate in a lifestyle change program. This program involves exercising more restraint and moderation with regard to bodily pleasures (alcohol, food, sex, etc.), for a period of three months. During these three months, Max has regularly avoided overindulging in these pleasures. He has greatly reduced his consumption of alcohol, fatty and sugary foods, and pornography. He has also lazed on the couch much less often, and has got into the habit of exercising regularly.

In the Indulgence condition, participants read a vignette about a target lead to increase his consumption of bodily pleasures in the last three months:

Three months ago, Max moved to another city for the purpose of his job. The neighborhood he now lives in has fewer gyms than his previous neighborhood. It also has many more bars, fast-food restaurants, and sex shops. As a result of this new environment, Max has indulged in bodily pleasures on a regular basis in the last three months, without restraint nor moderation. He has greatly increased his consumption of alcohol, fatty and sugary foods, and pornography. He has also lazed on the couch much more frequently in his free time.

In both conditions, the cause of the target's lifestyle change was described as exogenous to his internal dispositions (e.g. he moved, for reasons independent of the motivation to indulge, in a new area where indulgence happened to be more tempting). The goal was to make sure that the lifestyle change does not appear as a consequence of the target's character in the first place, and that participants' responses reflect the perceived effect of indulgence (vs. restraint) on character. Participants then completed a set of dependent measures, asking them to "indicate how Max's lifestyle change over the past months may have affected [several of his] character traits".

\section{Dependent measures}

Perceived change in cooperativeness. Participants answered 4 questions about whether Max had likely become more or less cooperative as a result of his lifestyle change over the past three months, such as: "As result of this lifestyle change, would you say that Max is now more or 
less likely to refuse to help a friend if he has better to do?". Answers were given on a scale from -3 (Much less) to 3 (Much more), with 0 indicating no perceived change (Neither more nor less). The other questions asked about perceived change in the target's likelihood "to cheat his partner if he had the chance" (reverse-coded), to "slack off and let colleagues to his part of the job" (reverse-coded) and to "give back a significant amount of money lent to him". The four questions had good reliability $(\alpha=0.91)$.

Perceived change in moral character. Providing a complementary measure of disposition to cooperative behavior, similar questions assessed participants' perception of the effect of Max's lifestyle change on his moral character: "As a result of this lifestyle change, would you say that Max is now more or less trustworthy / honest / reliable / loyal / responsible" (from - $3=$ Much less to $3=$ Much more, with $0=$ Neither more nor less). These traits were selected from previously established measures of moral character (Goodwin et al., 2013; Goodwin, 2015). The 5 questions had good reliability $(\alpha=0.94)$.

Perceived change in warmth and competence. Participants also completed measures of target's change in warmth and competence (Fiske et al., 2007), used only to disguise the aim of the study. As planned in the pre-registration, these measures were not analyzed.

Perceived change in trait-self-control. Six questions measured perception of the effect of the target's lifestyle change on his dispositional self-control. These questions were adapted and selected from the trait-self-control scale (Tangney et al., 2004), so that their target was not the self but the individual described on the vignette (e.g., "As a result of this lifestyle change, would you say that Max is now more or less able to work himself effectively toward long-term goals"). The six items had good reliability $(\alpha=0.96)$.

Moralization of harmless bodily pleasures. Four questions assessed participants' endorsement of puritanical values, by asking them to rate the moral desirability of several inherently harmless behaviors, from 1 = Highly morally undesirable to 7 = Highly morality desirable. These behaviors comprised: "Regularly drinking too much alcohol when one is alone after work", "Regularly eating to excess, in particular fat and sugar, to get as much pleasure as possible", "Taking pleasure in laziness on a regular basis", and "Masturbating regularly for the sake of pleasure". Notably, these questions assessed participants' condemnation of bodily pleasures in general, not their moralization of Max's behavior specifically. The 4 items showed acceptable reliability $(\alpha=0.77)$.

\section{Results}

Perceived effects of indulgence and restraint on cooperativeness, moral character, and trait-selfcontrol. Figure 1 summarizes the experimental effects. Confirming P1, lifestyle change characterized by increased indulgence in bodily pleasures was perceived as generating a more negative change in the target's cooperativeness $(M=-0.81, S D=0.86)$, compared to 
increased restraint $(M=0.97, S D=0.81), t(377)=-20.5, p<0.001, d=-2.11$. Importantly, mean rating of cooperativeness change was significantly lower than the 0 -point of the response scale in the indulgence condition, $t(193)=-13.07, p<0.001$, and significantly greater than the 0 -point of the scale in the restraint condition, $t(182)=16.11, p<0.001$. This indicates that, while increased indulgence was perceived as reducing the target's cooperativeness, increased restraint was perceived as increasing his cooperativeness (Figure 1.A).
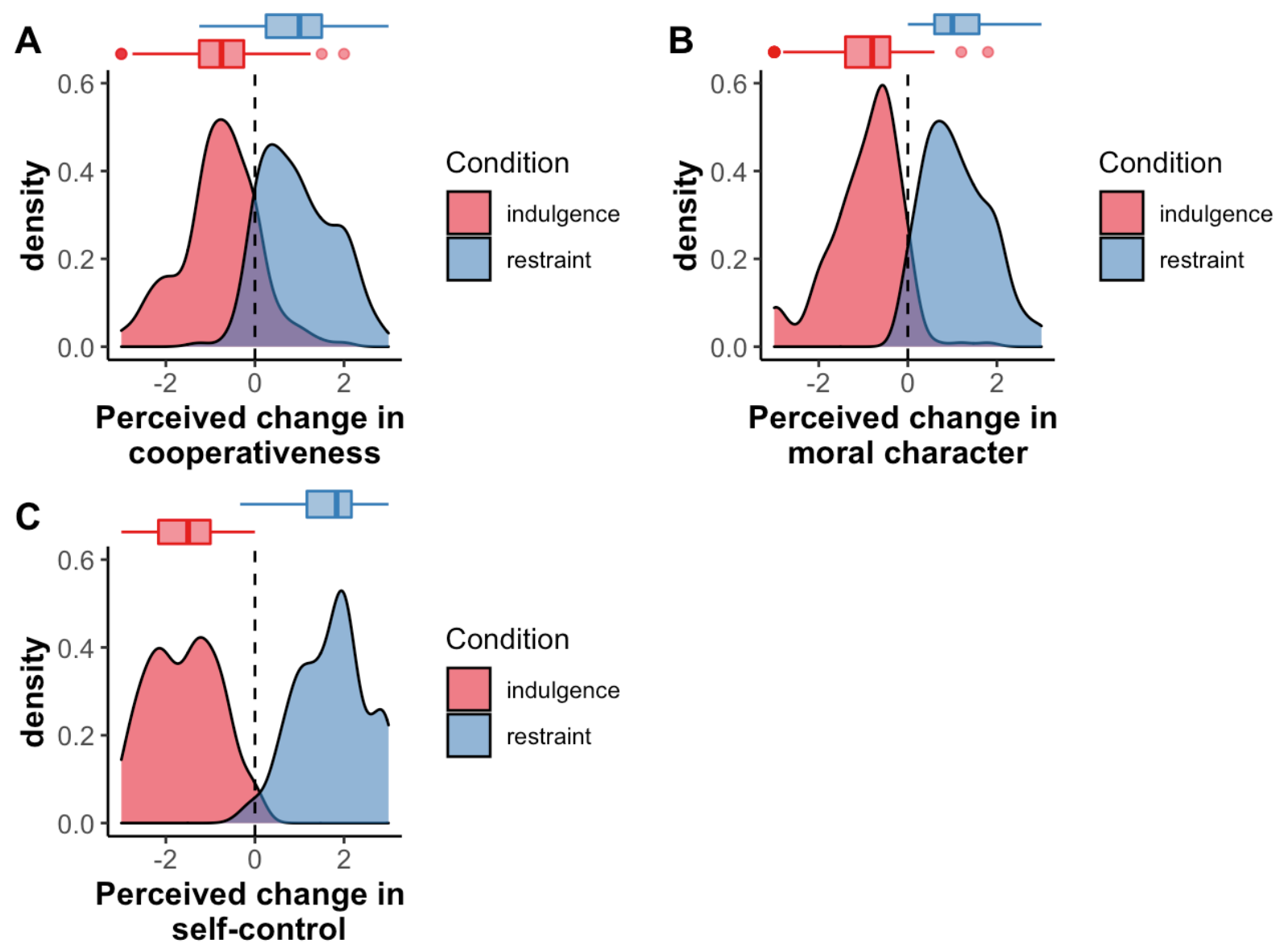

Figure 1.Distributions of perceived change in cooperativeness (A), moral character (B), and trait-self-control (C) of targets who increased (indulgence) vs. decreased (restraint) consumption of harmless bodily pleasures over the last three months. Vertical dashed lines correspond to no perceived change. Values inferior to 0 indicate perceived reduction in a given trait; values greater than 0 indicate perceived increase in the trait.

Supporting P2, increased indulgence in bodily pleasures was perceived as generating a more negative change in the target's moral character than increased restraint (indulgence: $M$ $=-0.97, S D=0.80$; restraint $\mathrm{M}=1.11, \mathrm{SD}=0.73), t(376)=-26.44, p<0.001, d=-2.71$. Mean rating of change in moral character was significantly lower than the 0 -point of the scale in the indulgence condition, $t(193)=-16.83, p<0.001$, and significantly greater than 0 in the restraint condition, $t(182)=20,65, p<0.001$. Thus, while increased indulgence was perceived as degrading moral character, increased restraint was perceived as improving moral character (Figure 1.B) 
In line with $\mathrm{P} 3$, as a result of increased indulgence, the target was also perceived as having undergone a much more negative change in trait-self-control $(M=-1.59, S D=0.78)$ compared to the restraint condition $(M=1.71, S D=0.78), t(375)=-41.16, p<0.001, d=-$ 4.23. Mean rating of trait-self-control change was again significantly lower than 0 in the indulgence condition, $t(193)=-28.31, p<0.001$, and significantly greater than 0 in the restraint condition, $t(182)=29.72, p<0.001$. This suggests that, while sustained indulgence was perceived as reducing self-control, sustained restraint was to the contrary perceived as increasing self-control (Figure 1.C).

\section{Perceived change in self-control predicts perceived change in cooperativeness and moral} character. We further predicted that participants' judgements about the target's change in cooperativeness (P4) and moral character (P5) would be predicted by their perceptions of the target's change in self-control, both within and across conditions. In line with these predictions, in the indulgence condition, the more participants' perceived indulgence as reducing the target's self-control, the more they perceived indulgence as reducing the target's cooperativeness, $r(192)=0.59, p<0.001$, and moral character, $r(192)=0.60, p<0.001$

(Figure 2). In the restraint condition, the perception that restraint increased self-control also predicted the perception that restraint improves cooperativeness, $r(181)=0.57, \mathrm{p}<0.001$, and moral character, $r(181)=0.57, p<0.001$ (Figure 2). Across conditions, perceptions of selfcontrol change were also strongly associated with perceptions of cooperativeness change, $r(377)=0.83, \mathrm{p}<0.001$, and moral character change, $r(377)=0.88, p<0.001$.


Figure 2. Relationships between perceived change in trait-self-control (following indulgence or restraint), and perceived change in cooperativeness (A) and moral character (B). Values inferior to 0 indicate perceived reduction in a given trait; values greater than 0 indicate perceived increase in the trait.

Mediation analyses. The Moral Disciplining Theory of puritanism posits that people perceive indulgence (vs restraint) as degrading cooperativeness because they perceive indulgence (vs. restraint) as degrading self-control, which they perceive necessary for 
cooperativeness (Fitouchi et al., 2021c). It thus follows that perceptions of self-control change would mediate the effects of condition (indulgence vs. restraint) on both perceptions of cooperativeness change and perceptions of moral character change, although this mediation prediction was not pre-specified in our pre-registration. Model-based mediation analyses were performed with R package “mediation” (Tingley et al., 2014). Perceptions of self-control change fully mediated the effect on condition on perception of cooperativeness change (Figure 3A). The indirect effect was estimated to be $2.04,95 \%$ CI [1.76, 2.31], $p<$ 0.001 , with 100 bootstrap samples, leaving a nonsignificant direct effect, $b=-.25,95 \%$ CI [$.52, .09], p=.14$. The proportion of effect mediated was $100 \%$, suggesting that people perceived sustained indulgence, as opposed to restraint, as altering cooperativeness exactly to the extent that they perceived it as altering self-control.

Perceived self-control change also fully mediated the effect of condition on perceived moral character change (Figure 3.B), with an indirect effect of 1.909, 95\% CI [1.67, 2.13], $p$ $<0.001$, leaving a nonsignificant indirect effect, $b=.17,95 \%$ CI [-.06, .05], $p=0.2$.

Proportion of effect mediated was $92 \%$, suggesting participants perceived indulgence, as opposed to restraint, as altering moral character almost exactly to the extent that they perceived indulgence (vs. restraint) as altering self-control.
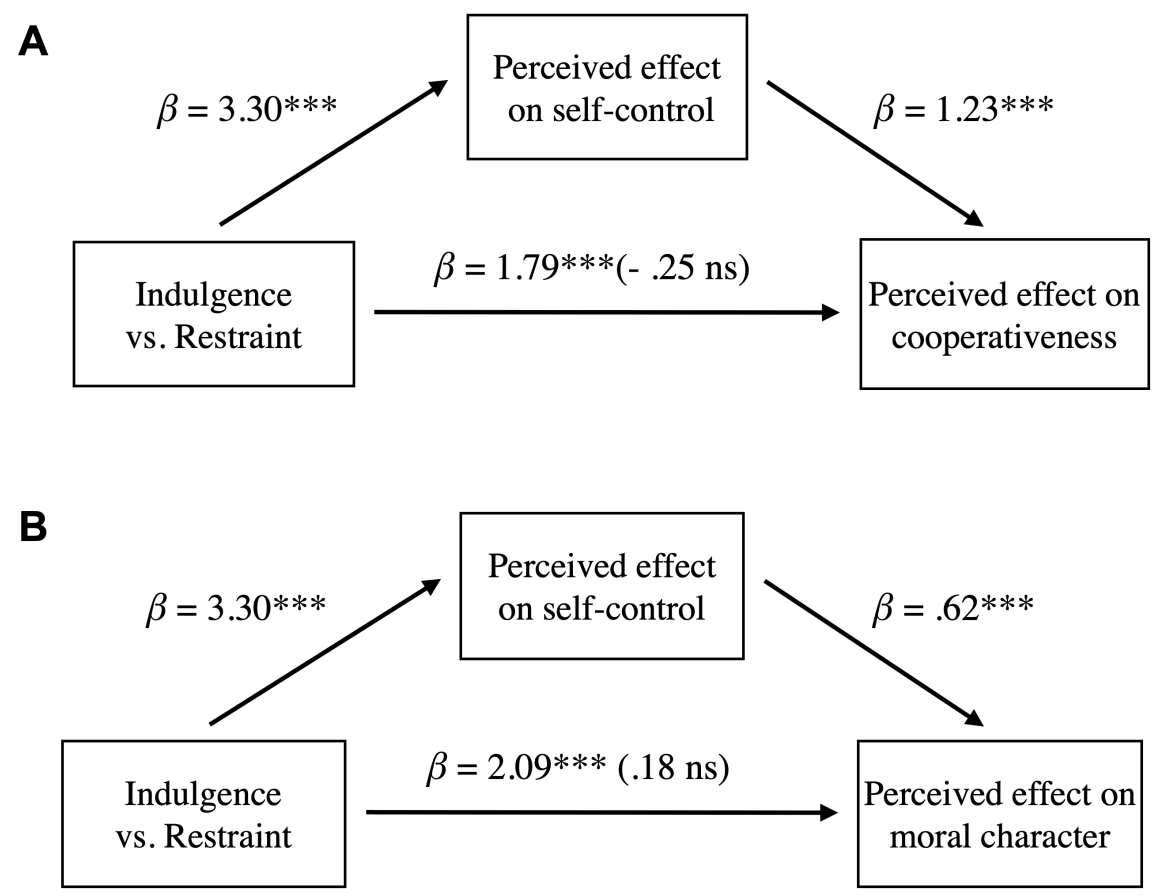

Figure 3. (A) Unstandardized regression coefficients for perceived effect of lifestyle change on cooperativeness as mediated by perceived effect on trait-self-control. (B) Perceived effect of lifestyle change on moral character as mediated by perceived effect on trait-self-control. On the center paths, the coefficients in parentheses are the direct effects, and the coefficients outside parentheses are the total effects $(* * *<<.001)$.

Moralizations of bodily pleasures. If bodily pleasures are moralized because perceived as increasing-by altering people's self-control — the probability of uncooperative behaviors, 
moral condemnation of bodily pleasures should be predicted by perceptions that they alter cooperativeness, moral character, and self-control. Our last pre-registered predictions were thus that, the more people perceive indulgence as reducing cooperativeness, the more they will rate harmless bodily pleasures as morally undesirable, whereas the more they perceive restraint as increasing cooperativeness, the more they will rate them as morally undesirable (P6). We similarly predicted that perceived effect of indulgence on moral character would negatively correlate with moralization, while perceived effect of restraint would positively correlate with moralization (P7). We also investigated the existence of such a differential effect on self-control, although this analysis was not on our pre-registration.

In line with these predictions, in the indulgence condition, the more people perceived that indulgence reduces cooperativeness, the more they morally condemned gluttony, drinking, masturbation and laziness, $r(192)=-0.31, \mathrm{p}<0.001$. Perception that indulgence alters moral character $r(192)=-0.56, \mathrm{p}<0.001$, and self-control, $r(192)=-0.36, \mathrm{p}<0.001$, also predicted moralization of bodily pleasures. In the restraint condition, puritanical moral judgements were also predicted by perception that restraint improves moral character, $r(181)$ $=0.15, \mathrm{p}<0.05$, and self-control, $r(181)=0.18, p<0.05$. However, P6 received only partial support, as the relationship between perception that restraint improves cooperativeness and condemnations of indulgence in bodily pleasures was not significant, $r(181)=0.12, \mathrm{p}=0.1$. Figure 4 summarizes these relationships.
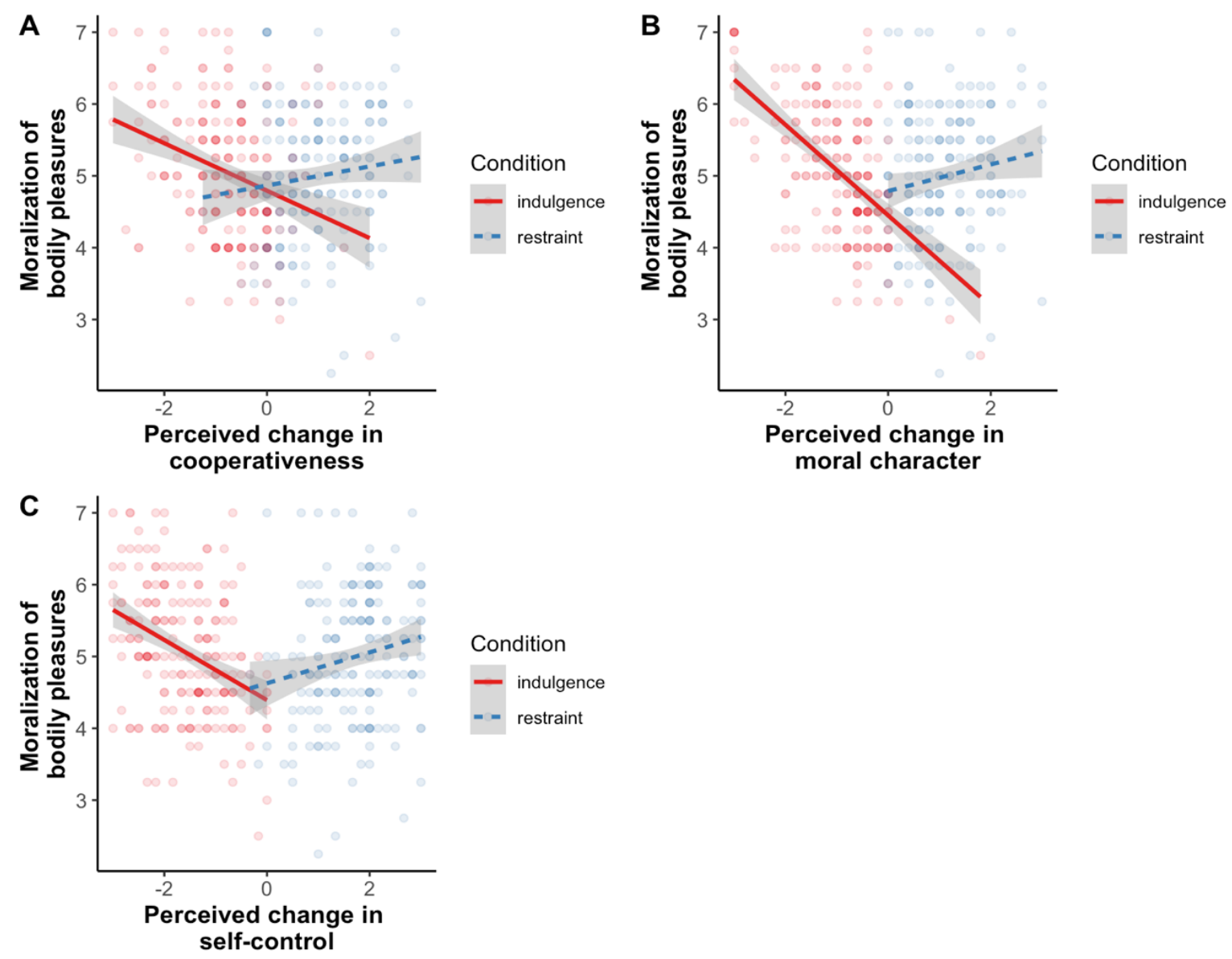
Figure 4. Relationships between puritanical moral judgements and perceptions that indulgence (or restraint) decreases (or increases) cooperativeness $(\mathrm{A})$, moral character $(\mathrm{B})$, and self-control $(\mathbf{C})$. Values inferior to 0 indicate perceived reduction in a given trait; values greater than 0 indicate perceived increase in the trait.

\section{Discussion}

Study 1 found that a target indulging in four bodily pleasures simultaneously was perceived as reducing his self-control and cooperativeness. It remains possible, however, that indulgence in only some of these four pleasures is responsible for the overall effect, whereas the other pleasures would not be seen as impacting self-control or cooperativeness.

Moreover, while perceiving indulgence as altering self-control and cooperativeness predicted condemnations of bodily pleasures, perceptions that restraint improves self-control and cooperativeness were less strongly and consistently associated with condemnation of bodily pleasures. This may stem from our moralization questions, which assessed the moral disapproval of indulgence rather than the praise of restraint. But this may also stem from puritanical moralizations being actually more strongly driven by perceived negative effects of indulgence rather than positive effects of restraint. Study 2 addresses these two issues.

\section{Study 2}

Study 2 investigated whether each bodily pleasure-gluttony, masturbation, alcohol, and laziness - was independently perceived as decreasing self-control and thus cooperativeness. It thus presented participants with targets led to increase (or decrease) indulgence in only one bodily pleasure at a time, resulting in eight different conditions: Food-Indulgence, FoodRestraint; Sex-Indulgence, Sex-Restraint; Alcohol-Indulgence, Alcohol-Restraint; LazinessIndulgence, Laziness-Restraint.

In the Restraint conditions, puritanical moralizations were assessed in terms of moral praise of restraint (rather than disapproval of indulgence). This was to determine whether, in Study 1, the weaker correlations between moralization of bodily pleasures and perceptions that restraint improves self-control and cooperativeness were only due to question framing.

\section{Methods}

Pre-registration. Design and predictions for this study were pre-registered prior to data collection. Pre-registration, data, and analysis scripts are available at https://osf.io/52thu/.

Participants. 720 American participants (90 in each condition; 358 males, 358 females, 4 unknown; $\left.M_{\text {age }}=36.81, S D_{\text {age }}=12.49\right)$ were recruited from www.prolific.co. Pre-registered sample size was determined by a priori power analysis. In Study 1, the smallest correlation between moralization of bodily pleasures and perceived cooperativeness degradation following indulgence was $\sim 0.30$. The number of participants required to achieve $80 \%$ power to detect such an effect within each "indulgence" condition in the current design is $82(\alpha=0.05)$. Our target sample size thus provides better than $80 \%$ power for our main correlational predictions. 
Twenty-four participants who failed the attention check were excluded from the sample, bringing sample size to 696 .

Procedure. The procedure was similar to Study 1. After consenting, participants were randomly assigned to one of eight conditions: Food-indulgence, Food-restraint, SexIndulgence, Sex-Restraint, Alcohol-Indulgence, Alcohol-Restraint, Laziness-Indulgence, Laziness-Restraint (see Supplementary Materials for a description of the 8 vignettes).

Participants in all conditions completed measures of perceived change in cooperativeness $(\alpha=0.87)$, perceived change in moral character $(\alpha=0.92)$, perceived change in trait-self-control $(\alpha=0.94)$, warmth $(\alpha=0.82)$, and competence $(\alpha=0.90)$, identical to those of Study 1. In the four Indulgence conditions, participants completed measures of moral disapproval of indulgence in bodily pleasures identical to those of Study 1 (e.g., "masturbating regularly for the sake of pleasure") ( $\alpha=0.73$ ). Unlike in Study 1 , moralizations questions in the four restraint conditions were framed in terms of moral praise of restraint from bodily pleasures (e.g., "refraining from masturbating too frequently", "avoiding drinking too much alcohol when one is alone after work") $(\alpha=0.87)$.

\section{Results}

Do people perceive drinking, gluttony, masturbation, and laziness as decreasing self-control and cooperativeness? Collapsing across domains of pleasure (sex, food, alcohol, laziness), indulgence was perceived as generating a significantly negative change in the target's cooperativeness, $M=-0.42, S D=0.84, t(348)=-9.3, p<.001$, moral character, $M=-0.49$, $S D=0.84, t(348)=-11.1, p<.001$, and self-control, $M=-1.06, S D=0.93, t(348)=-21.4, p$ $<.001$. By contrast, restraint across domains of pleasure was perceived as generating a significantly positive change in the target's cooperativeness, $M=0.58, S D=0.80, t(346)=$ $13.4, p<.001$, moral character, $M=0.75, S D=0.75, t(346)=18.7, p<.001$, and self-control, $M=1.11, S D=0.76, t(346)=27.3, p<.001$. This replicates the basic finding of Study 1 .

Taking each domain of pleasure separately, indulgence in masturbation, gluttony, drinking, and laziness were each independently perceived as more negatively affecting the target's cooperativeness, self-control, and moral character, compared to restraint from those pleasures (Table 1; Figure 5). To investigate whether this effect varied by domain, we regressed target behavior (Indulgence vs. Restraint), domain (sex, food, alcohol, laziness), and their interaction on perceived change in cooperativeness, using contrast coding for the levels of the domain and behavior variables. There was a significant interaction between domain and behavior. Indulging in alcohol was perceived as more negatively affecting the target's cooperativeness, compared to the mean effect of indulgence across domains of pleasure, $b=-$ $0.42, t(688)=-8.45, p<.001$. By contrast, indulging in sex, $b=0.12, t(688)=2.29, p=.02$, and food, $b=0.27, t(688)=5.17, p<.001$, was perceived as less negatively affecting the target's cooperativeness, compared to the mean effect across domains of pleasure. The same models for perceived change in self-control and moral character yield similar results (see Supplementary Materials for full statistics). 
Table 1. Perceived effect of target behavior in each domain of pleasure (sex, food, alcohol, laziness) on target's cooperativeness, moral character, and self-control in Study 2.

\begin{tabular}{|c|c|c|c|c|c|c|c|c|c|}
\hline & \multicolumn{3}{|c|}{$\begin{array}{l}\text { Food indulgence } \\
\qquad(n=87)\end{array}$} & \multicolumn{3}{|c|}{$\begin{array}{l}\text { Food restraint } \\
\qquad(n=83)\end{array}$} & \multicolumn{3}{|c|}{$\begin{array}{l}\text { Difference between } \\
\text { group means }\end{array}$} \\
\hline & $M$ & $S D$ & $p$ & $M$ & $S D$ & $p$ & $t$ & $p$ & $d$ \\
\hline Cooperativeness change & -0.11 & 0.55 & .056 & 0.34 & 0.66 & $<.001$ & -4.87 & $<.001$ & -0.75 \\
\hline Moral character change & -0.22 & 0.50 & $<.001$ & 0.50 & 0.57 & $<.001$ & -8.79 & $<.001$ & -1.35 \\
\hline \multirow[t]{3}{*}{ Self-control change } & -1.20 & 0.80 & $<.001$ & 1.09 & 0.69 & $<.001$ & -19.98 & $<.001$ & -3.05 \\
\hline & \multicolumn{3}{|c|}{$\begin{array}{l}\text { Alcohol indulgence } \\
\qquad(n=87)\end{array}$} & \multicolumn{3}{|c|}{$\begin{array}{l}\text { Alcohol restraint } \\
\qquad(n=89)\end{array}$} & \multicolumn{3}{|c|}{$\begin{array}{l}\text { Difference between } \\
\text { group means }\end{array}$} \\
\hline & $M$ & $S D$ & $p$ & $M$ & $S D$ & $p$ & $t$ & $p$ & $d$ \\
\hline Cooperativeness change & -0.79 & 0.92 & $<.001$ & 1.06 & 0.90 & $<.001$ & -13.44 & $<.001$ & -2.03 \\
\hline Moral character change & -0.92 & 0.91 & $<.001$ & 1.27 & 0.71 & $<.001$ & -17.78 & $<.001$ & -2.69 \\
\hline \multirow[t]{3}{*}{ Self-control change } & -1.36 & 0.98 & $<.001$ & 1.35 & 0.73 & $<.001$ & -20.89 & $<.001$ & -3.16 \\
\hline & \multicolumn{3}{|c|}{$\begin{array}{l}\text { Sexual indulgence } \\
\qquad(n=87)\end{array}$} & \multicolumn{3}{|c|}{$\begin{array}{l}\text { Sexual restraint } \\
\quad(n=89)\end{array}$} & \multicolumn{3}{|c|}{$\begin{array}{l}\text { Difference between } \\
\text { group means }\end{array}$} \\
\hline & $M$ & $S D$ & $p$ & $M$ & $S D$ & $p$ & $t$ & $p$ & $d$ \\
\hline Cooperativeness change & -0.34 & 0.98 & .0019 & 0.42 & 0.67 & $<.001$ & -5.94 & $<.001$ & -0.90 \\
\hline Moral character change & -0.35 & 0.94 & $<.001$ & 0.54 & 0.78 & $<.001$ & -6.86 & $<.001$ & -1.04 \\
\hline \multirow[t]{3}{*}{ Self-control change } & -0.82 & 1.10 & $<.001$ & 0.89 & 0.84 & $<.001$ & -11.57 & $<.001$ & -1.75 \\
\hline & \multicolumn{3}{|c|}{$\begin{array}{l}\text { Laziness indulgence } \\
\qquad(n=88)\end{array}$} & \multicolumn{3}{|c|}{$\begin{array}{l}\text { Laziness restraint } \\
\qquad(n=86)\end{array}$} & \multicolumn{3}{|c|}{$\begin{array}{l}\text { Difference between } \\
\text { group means }\end{array}$} \\
\hline & $M$ & $S D$ & $p$ & $M$ & $S D$ & $p$ & $t$ & $p$ & $d$ \\
\hline Cooperativeness change & -0.43 & 0.68 & $<.001$ & 0.47 & 0.74 & $<.001$ & -8.29 & $<.001$ & -1.26 \\
\hline Moral character change & -0.48 & 0.76 & $<.001$ & 0.67 & 0.65 & $<.001$ & -10.78 & $<.001$ & -1.63 \\
\hline Self-control change & -0.86 & 0.67 & $<.001$ & 1.11 & 0.68 & $<.001$ & -19.04 & $<.001$ & -2.89 \\
\hline
\end{tabular}



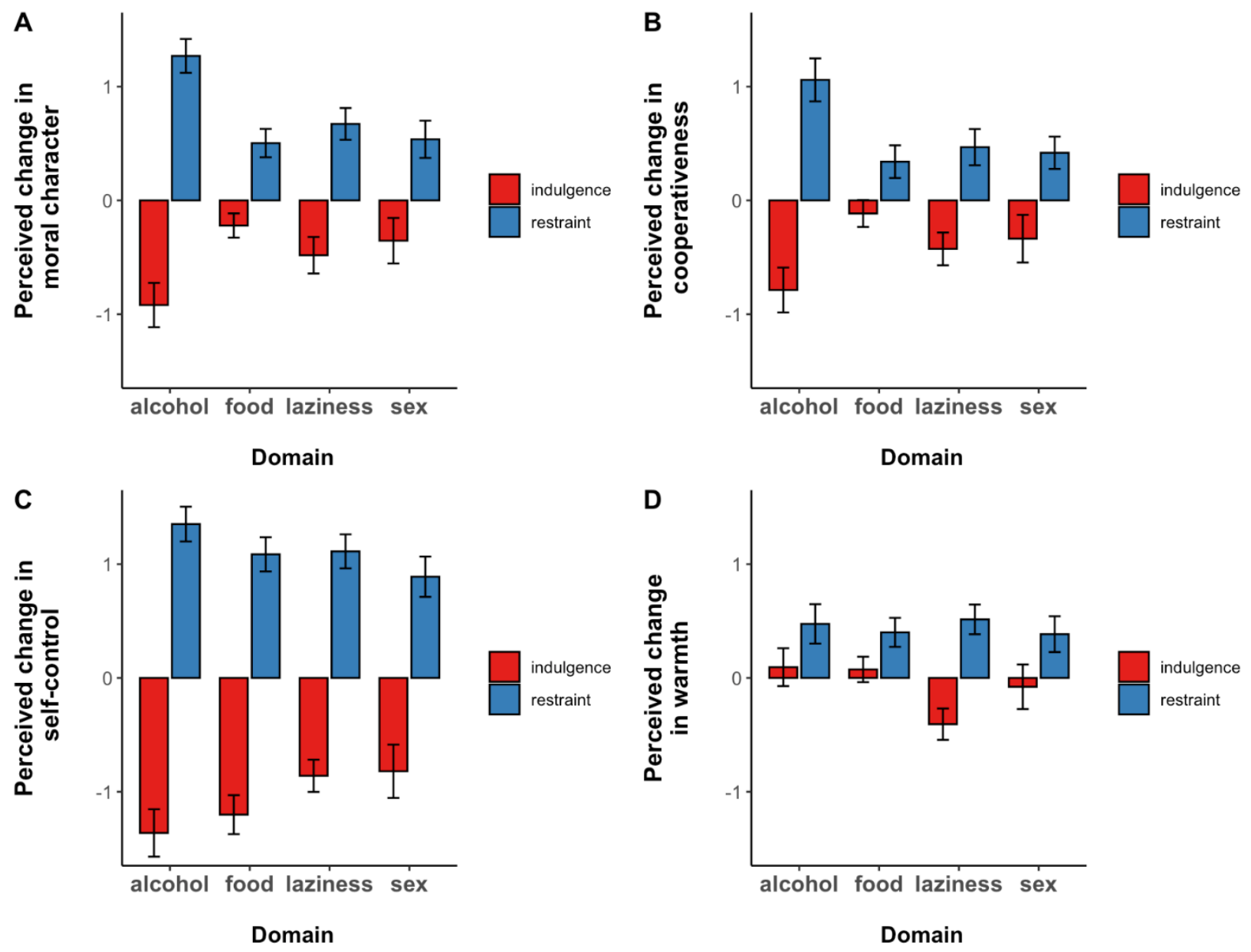

Figure 5. Mean perceived change in moral character (A), cooperativeness (B), self-control (C), and warmth (D) for targets who increased (indulgence) vs. decreased (restraint) their indulgence in alcohol, sex, food, or laziness $(* * *$ < .001). Values inferior to 0 indicate perceived reduction in a given trait; values greater than 0 indicate perceived increase in the trait. Error bars represent the $95 \%$ confidence intervals.

To rule out halo effects (i.e., overgeneralization of positive traits) (Nisbett $\&$ Wilson, 1977) and demand characteristics (Nichols \& Maner, 2008) as alternative explanations of our results, exploratory analyses tested whether the effects observed for self-control, cooperativeness, and moral character, also emerged for perceived change in warmth. Indeed, previous evidence suggests that warmth perceptions are partly dissociated from perceptions of trustworthiness/moral character (Goodwin et al., 2013; Goodwin, 2015), as well as from perceptions of self-control (Gai \& Bhattacharjee, 2022). While indulgence in each bodily pleasure was perceived as decreasing self-control, cooperativeness, and moral character, the perceived effect of indulgence on warmth was less consistent (Figure 5). Mean perceived change in warmth was not significantly different from zero in the food-indulgence condition, $M=0.07, S D=0.52, t(86)=1.33, p=0.19$, the alcohol-indulgence condition, $M=0.09, S D$ $=0.78, t(86)=1.13, p=0.26$, as well as in the sex-indulgence condition, $M=-0.78, S D=$ $0.92, t(86)=-0.79, p=0.43$ (Figure 5). This suggests that the effects observed for selfcontrol, cooperativeness, and moral character are not due to participants indiscriminately rating indulgent targets negatively in all respects. 
Does perceived change in self-control predict perceived change in cooperativeness and moral character? Although these analyses where not pre-specified in our pre-registration, we replicate the finding from Study 1 that perception that indulgence (across domains of pleasures) decreases self-control predicts perceptions that indulgence decreases cooperativeness, $r(347)=0.61, p<.001$, and moral character, $r(347)=0.57, p<.001$. Perceptions that restraint (across domains of pleasures) improves self-control also predicts perceptions that restraint improves cooperativeness, $r(345)=0.66, p<.001$, and moral character, $r(345)=0.65, p<.001$. These correlations were also found in each domain of pleasure separately (Figure 6; see Supplementary Material for full statistics).
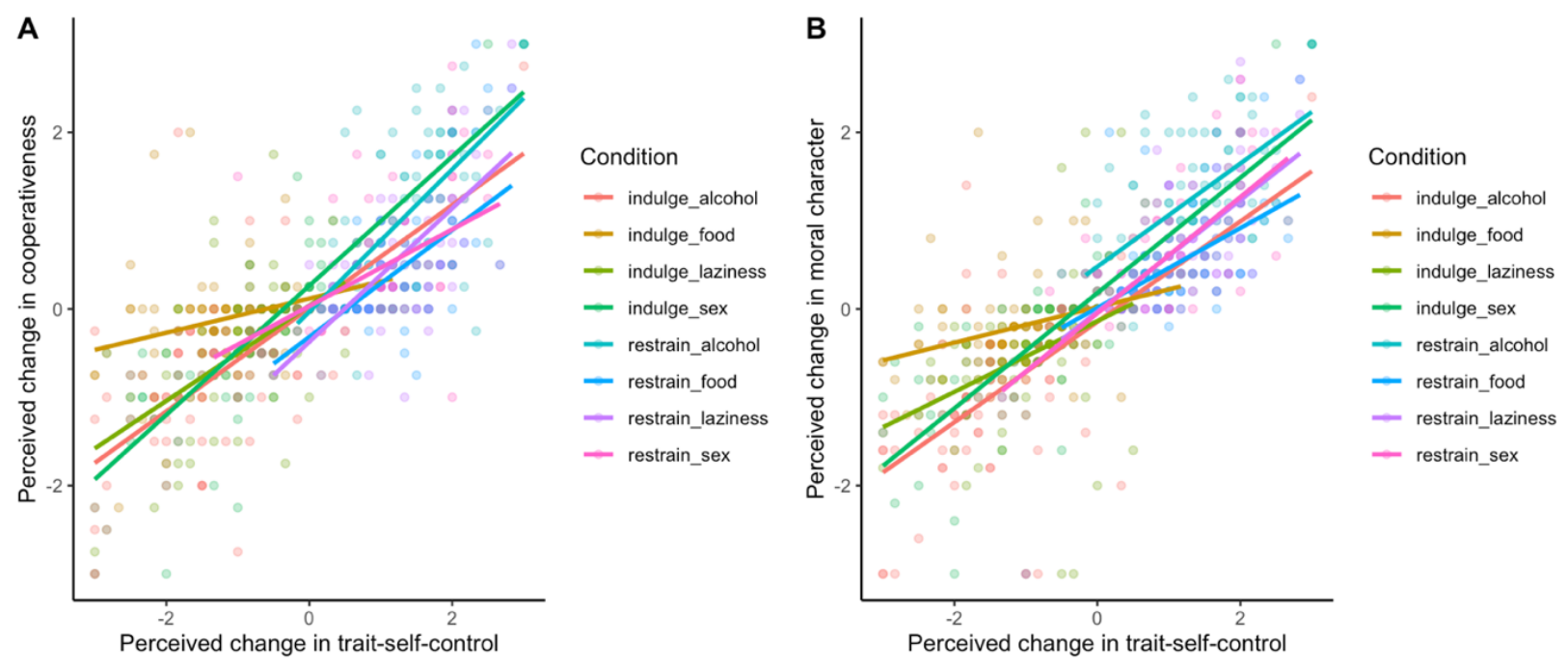

Figure 6. Relationships between perceived change in trait-self-control (following indulgence or restraint in one bodily pleasure), and perceived change in cooperativeness (A) and moral character (B). Values inferior to 0 indicate perceived reduction in a given trait; values greater than 0 indicate perceived increase in the trait.

Does perceived change in self-control mediate the perceived effect of indulgence (vs. restraint) on cooperativeness and moral character? Replicating Study 1, when collapsing all domains of pleasure, perceived change in self-control fully mediated the effect of indulgence (vs. restraint) on perceived change in cooperativeness $(A C M E=1.30, \mathrm{CI}[1.14,1.44], p<$ 0.001, $A D E=-0.291$, CI [-0.44, -0.15], $p<.001$, Prop. mediated: 100\%), and perceived change in moral character $(A C M E=1.22, \mathrm{CI}[1.10,1.34], p<.001, A D E=0.021, \mathrm{CI}[-0.12$, -0.14], $p=0.74$, Prop. mediated: 98\%).

These mediations hold for each bodily pleasure independently (see Supplementary Materials for full statistics). Perceived change in self-control fully mediated the effect of indulgence in (vs. restraint from) gluttony, masturbation, and laziness on both cooperativeness and moral character. For alcohol, perceived change in self-control fully mediated the effect of indulgence on perceived change in cooperativeness, but only partially mediated its effect on moral character, $A C M E=1.55, C I[1.23,1.87], p<.001 ; A D E=0.64$, $C I[0.30,1.05], p<.001$; Prop. mediated: $71 \%$. 
Correlations with puritanical moral judgements. Collapsing all domains of pleasure, moral condemnation of indulgence was predicted by perception that indulgence decreases selfcontrol, $r(347)=-.37, p<.001$, cooperativeness, $r(347)=-.27, p<.001$, and moral character $r(347)=-.35, p<.001$. Moral praise of restraint was also predicted by perception that restraint improves self-control, $r(345)=.26, p<.001$, cooperativeness, $r(345)=.20, p<.001$, and moral character, $r(345)=.17, p=.0016$.

Exploratory analyses tested whether the association between puritanical moralizations and perceptions of cooperativeness, self-control, and character change were stronger for certain bodily pleasures. No significant interaction was found between domain (sex, food, alcohol, laziness), and perceptions of self-control change, cooperativeness, or character change (see Supplementary Materials). In other words, puritanical moralizations were not more strongly associated with perceiving one bodily pleasure, more than others, as decreasing self-control, cooperativeness or moral character.

\section{Discussion}

In addition to replicating overall effects from Study 1, Study 2 supports the idea that each bodily pleasure - sex, food, alcohol, laziness—is independently perceived as reducing cooperativeness by altering self-control. While perceptions that restraint improves selfcontrol and cooperativeness appear more strongly related to moral valorization of restraint than to moral condemnation of indulgence as assessed in Study 1, these associations still appear somewhat weaker than relationships between moral condemnation of indulgence and perceptions that indulgence alters self-control and cooperativeness. This suggests that puritanical moralizations may be more strongly driven by perceived negative effects of indulgence than by perceived positive effects of restraint.

\section{General discussion}

These studies find support for the idea that harmless bodily pleasures are moralized because they are perceived as indirectly affecting cooperation, through their effects on self-control. These findings support the central contention of the Moral Disciplining Theory of puritanism (Fitouchi et al., 2021c). We indeed find evidence that (a) people perceive indulgence in several bodily pleasures as reducing self-control, cooperativeness, and moral character, while moderation improves self-control, cooperativeness, and character; (b) the perceived effect of indulgence (vs. restraint) on cooperativeness and moral character is fully mediated by the perceived effect of indulgence (vs. restraint) on self-control; and (c) this perception that indulgence has deleterious effects on self-control, character, and cooperativeness predicts moral condemnation of harmless bodily pleasures.

\section{Implications}

"Purity" values have sparked intense debates in moral psychology: is human morality unified by its functional relationship to cooperation? Is morality about more than harm and 
fairness? (Baumard et al., 2013b; Beal, 2020; Curry, Jones Chesters, et al., 2019; Curry, Mullins, et al., 2019; Goodwin, 2017; Graham et al., 2013; Greene, 2015; Piazza et al., 2019; Schein \& Gray, 2018). Condemnations of purity violations (e.g., gluttony, lustful sexuality, intoxicants) have widely appeared as a critical argument in those debates. Being both inherently harmless and morally condemned, purity violations would show that moral mind is not only sensitive to cooperation-related challenges, but also to disgust-based concerns for sacredness and the purity of the soul (Graham et al., 2013; Graham \& Haidt, 2012; Haidt, 2012; Haidt \& Graham, 2007; Horberg et al., 2009). Our results contribute to this debate by suggesting that "impure" behaviors, although inherently harmless (e.g., gluttony, masturbation, drinking in private), can in fact be perceived as indirectly affecting cooperative interactions - and are thus, despite appearances, within the explanatory reach of cooperationbased theories of morality. These results add to a body of research suggesting that "harmless crimes" are in fact perceived by people as socially harmful (Gray et al., 2014; Royzman et al., 2009, 2015; Schein et al., 2016), and that perceptions of harm may more robustly predict their moralization than disgust or disgust-sensitivity (Schein et al., 2016; see also Gray \& Schein, 2016).

Our findings also adds to recent work suggesting the importance of taking into account people's lay theories of human behavior for explaining moral judgements and their variations (Fitouchi et al., 2021c; Fitouchi \& Singh, 2021; Moon et al., 2021; Nettle \& Saxe, 2021). Puritanical condemnations, our results suggest, may stems from lay beliefs that repeatedly indulging in bodily pleasures would impair people's self-control, thus making future temptations - including uncooperative ones-harder to resist. This is consistent with recent evidence for the importance of lay theories of self-control in the moralization of immodesty - another puritanical norm. Moon et al. (2021) indeed found that lay beliefs that males have low sexual self-control predict the moralization of female immodest clothing. Although inherently harmless, immodesty seems perceived as indirectly favoring socially harmful behaviors by triggering hard-to-control sex drives in impulsive males (Moon et al., 2021). Besides puritanical values, Nettle \& Saxe (2021) recently found evidence that authoritarian values stem from the lay theory that people-in particular when under conditions of war and scarcity - are not spontaneously motivated to behave cooperatively, so that strong, punitive leaders appear necessary to ensure their cooperation (see also Crimston et al., 2021).

Finally, this study contributes to the literature on the role of perceived self-control in inferences about others' trustworthiness and moral character. Previous experimental evidence have suggested that, when seeing other individuals indulge in immediate pleasure, people infer that these individuals have low self-control, and accordingly judge them to be less trustworthy (Gai \& Bhattacharjee, 2022; Merritt, 2013; Righetti \& Finkenauer, 2011). Our results confirm that perceptions of others' self-control, trustworthiness, and moral character are strongly related. In addition, they suggest that indulgence in short-term temptations is perceived not only as a cue of low trustworthiness or bad moral character, but also as having a causal effect on people's trustworthiness and character-by not only revealing, but also causally affecting their ability to resist temptations. 


\section{Limitations and future directions}

Our experimental manipulation supports the idea that people perceive indulgence, as opposed to restraint, as having more negative effects on self-control and cooperativeness. However, this study only provides correlational evidence for the relationship between moralization of bodily pleasures and perception that they reduce self-control and cooperativeness. Future studies may experimentally investigate the effect of perceptions of indulgence's effect on participants moral judgements. Finally, our findings only derive from a single participant pool of American adults. Future research should of course investigate the replicability and generalizability of these results in other populations-in particular in more puritanical countries.

\section{References}

Alexander, R. D. (1987). The biology of moral systems. A. de Gruyter.

André, J.-B., Debove, S., Fitouchi, L., \& Baumard, N. (2022). Moral cognition as a Nash product maximizer: An evolutionary contractualist account of morality [Preprint]. PsyArXiv. https://doi.org/10.31234/osf.io/2hxgu

Axelrod, R. M. (2006). The evolution of cooperation (rev. ed). Basic Books.

Baumard, N., André, J.-B., \& Sperber, D. (n.d.). Partner choice, fairness, and the extension of morality. Behavioral and Brain Sciences.

Baumard, N., André, J.-B., \& Sperber, D. (2013). A mutualistic approach to morality: The evolution of fairness by partner choice. Behavioral and Brain Sciences, 36(01), 5978. https://doi.org/10.1017/S0140525X11002202

Beal, B. (2020). What Are the Irreducible Basic Elements of Morality? A Critique of the Debate Over Monism and Pluralism in Moral Psychology. Perspectives on Psychological Science, 15(2), 273-290. https://doi.org/10.1177/1745691619867106

Beckmann, N. (2010). Pleasure and danger: Muslim views on sex and gender in Zanzibar. Culture, Health \& Sexuality, 12(6), 619-632. https://doi.org/10.1080/13691051003663713 
Bradley, D. F., Grubbs, J. B., Uzdavines, A., Exline, J. J., \& Pargament, K. I. (2016). Perceived Addiction to Internet Pornography among Religious Believers and Nonbelievers. Sexual Addiction \& Compulsivity, 23(2-3), 225-243. https://doi.org/10.1080/10720162.2016.1162237

Burnette, J. L., Davisson, E. K., Finkel, E. J., Van Tongeren, D. R., Hui, C. M., \& Hoyle, R. H. (2014). Self-Control and Forgiveness: A Meta-Analytic Review. Social Psychological and Personality Science, 5(4), 443-450. https://doi.org/10.1177/1948550613502991

Buyukcan-Tetik, A., Finkenauer, C., Siersema, M., Vander Heyden, K., \& Krabbendam, L. (2015). Social Relations Model Analyses of Perceived Self-Control and Trust in Families. Journal of Marriage and Family, 77(1), 209-223. https://doi.org/10.1111/jomf.12154

Buyukcan-Tetik, A., \& Pronk, T. (2021). Partner self-control and intrusive behaviors: A gender-specific examination of the mediating role of trust. Current Psychology, 3. https://doi.org/10.1007/s12144-021-02462-4

Cameron, C. D., Lindquist, K. A., \& Gray, K. (2015). A constructionist review of morality and emotions: No evidence for specific links between moral content and discrete emotions. Personality and Social Psychology Review, 19(4), 371-394.

Celniker, J., Gregory, A., Koo, H., Piff, P. K., Ditto, P., \& Shariff, A. (2020). The Moralization of Unproductive Effort [Preprint]. PsyArXiv. https://doi.org/10.31234/osf.io/nh9ax

Cohen, J. (1988). Statistical power analysis for the behavioral sciences. Lawrence Erlbaum Associates. Hillsdale, NJ, 20-26.

Cohen, T. R., Panter, A. T., Turan, N., Morse, L., \& Kim, Y. (2014). Moral character in the workplace. Journal of Personality and Social Psychology, 107(5), 943. 
Crawford, J. T., Inbar, Y., \& Maloney, V. (2014). Disgust sensitivity selectively predicts attitudes toward groups that threaten (or uphold) traditional sexual morality. Personality and Individual Differences, 70, 218-223. https://doi.org/10.1016/j.paid.2014.07.001

Curry, O. S. (2016). Morality as Cooperation: A Problem-Centred Approach. In T. K. Shackelford \& R. D. Hansen (Eds.), The Evolution of Morality (pp. 27-51). Springer International Publishing. https://doi.org/10.1007/978-3-319-19671-8_2

Curry, O. S., Jones Chesters, M., \& Van Lissa, C. J. (2019). Mapping morality with a compass: Testing the theory of 'morality-as-cooperation' with a new questionnaire. Journal of Research in Personality, 78, 106-124. https://doi.org/10.1016/j.jrp.2018.10.008

Curry, O. S., Mullins, D. A., \& Whitehouse, H. (2019). Is It Good to Cooperate? Testing the Theory of Morality-as-Cooperation in 60 Societies. Current Anthropology, 60(1), 4769. https://doi.org/10.1086/701478

Dabhoiwala, F. (2012). The origins of sex: A history of the first sexual revolution. Oxford University Press.

Doniger, W. (2014). On Hinduism. Oxford University Press.

Droubay, B. A., \& Butters, R. P. (2020). Pornography, religiosity, and social work. Journal of Social Work, 20(5), 557-575. https://doi.org/10.1177/1468017319852599

Edelstein, O. E., Wacht, O., Grinstein-Cohen, O., Reznik, A., Pruginin, I., \& Isralowitz, R. (2020). Does religiosity matter? University student attitudes and beliefs toward medical cannabis. Complementary Therapies in Medicine, 51, 102407. https://doi.org/10.1016/j.ctim.2020.102407 
Fan, W., Ren, M., Zhang, W., Xiao, P., \& Zhong, Y. (2020). Higher Self-Control, Less Deception: The Effect of Self-Control on Deception Behaviors. Advances in Cognitive Psychology, 16(3), 228-241. https://doi.org/10.5709/acp-0299-3

Fehr, E., \& Leibbrandt, A. (2011). A field study on cooperativeness and impatience in the Tragedy of the Commons. Journal of Public Economics, 95(9-10), 1144-1155. https://doi.org/10.1016/j.jpubeco.2011.05.013

Fiske, S. T., Cuddy, A. J. C., \& Glick, P. (2007). Universal dimensions of social cognition: Warmth and competence. Trends in Cognitive Sciences, 11(2), 77-83. https://doi.org/10.1016/j.tics.2006.11.005

Fitouchi, L., André, J.-B., \& Baumard, N. (2021a). Are there really so many moral emotions? Carving morality at its functional joints.

Fitouchi, L., André, J.-B., \& Baumard, N. (2021b). The intertwined cultural evolution of ascetic spiritualities and puritanical religions as technologies of self-discipline.

Fitouchi, L., André, J.-B., \& Baumard, N. (2021c). Moral disciplining: The cognitive and evolutionary foundations of puritanical morality. PsyArXiv. https://doi.org/10.31234/osf.io/2stcv

Fitouchi, L., \& Singh, M. (2021). Supernatural punishment beliefs as cognitively compelling tools of social control. Current Opinion in Psychology, S2352250X21001937. https://doi.org/10.1016/j.copsyc.2021.09.022

Gaca, K. L. (2003). The Making of Fornication: Eros, Ethics, and Political Reform in Greek Philosophy and Early Christianity. University of California Press.

Gai, P. J., \& Bhattacharjee, A. (2022). Willpower as moral ability. Journal of Experimental Psychology: General. https://doi.org/10.1037/xge0001169

Garden, K. (2014). The first Islamic reviver: Abū Hämid al-Ghazālī and his Revival of the religious sciences. Oxford University Press. 
Ghelfi, E., Christopherson, C. D., Urry, H. L., Lenne, R. L., Legate, N., Fischer, M. A., Wagemans, F. M. A., Wiggins, B., Barrett, T., Bornstein, M., Haan, B. de, Guberman, J., Issa, N., Kim, J., Na, E., O’Brien, J., Paulk, A., Peck, T., Sashihara, M., ... Sullivan, D. (2020). Reexamining the Effect of Gustatory Disgust on Moral Judgment: A Multilab Direct Replication of Eskine, Kacinik, and Prinz (2011): Advances in Methods and Practices in Psychological Science. https://doi.org/10.1177/2515245919881152

Glucklich, A. (2020). The Joy of Religion: Exploring the Nature of Pleasure in Spiritual Life. Cambridge University Press.

Goode, E., \& Ben-Yehuda, N. (2010). Moral panics: The social construction of deviance. Wiley Online Library.

Goodwin, G. P. (2015). Moral Character in Person Perception. Current Directions in Psychological Science, 24(1), 38-44. https://doi.org/10.1177/0963721414550709

Goodwin, G. P. (2017). Is morality unified, and does this matter for moral reasoning? In Moral inferences (pp. 17-44). Psychology Press.

Goodwin, G., Piazza, J., \& Rozin, P. (2013). Moral Character Predominates in Person Perception and Evaluation. Journal of Personality and Social Psychology, 106. https://doi.org/10.1037/a0034726

Graham, J., \& Haidt, J. (2012). Sacred values and evil adversaries: A moral foundations approach. The Social Psychology of Morality: Exploring the Causes of Good and Evil, $11-31$.

Graham, J., Haidt, J., Koleva, S., Motyl, M., Iyer, R., Wojcik, S. P., \& Ditto, P. H. (2013). Moral Foundations Theory. In Advances in Experimental Social Psychology (Vol. 47, pp. 55-130). Elsevier. https://doi.org/10.1016/B978-0-12-407236-7.00002-4 
Gray, K., \& Schein, C. (2016). No Absolutism Here: Harm Predicts Moral Judgment 30× Better Than Disgust—Commentary on Scott, Inbar, \& Rozin (2016). Perspectives on Psychological Science, 11(3), 325-329. https://doi.org/10.1177/1745691616635598

Gray, K., Schein, C., \& Ward, A. F. (2014). The myth of harmless wrongs in moral cognition: Automatic dyadic completion from sin to suffering. Journal of Experimental Psychology: General, 143(4), 1600-1615. https://doi.org/10.1037/a0036149

Greene, J. D. (2015). The rise of moral cognition. Cognition, 135, 39-42. https://doi.org/10.1016/j.cognition.2014.11.018

Grubbs, J. B., Grant, J. T., \& Engelman, J. (2018). Self-identification as a pornography addict: Examining the roles of pornography use, religiousness, and moral incongruence. Sexual Addiction \& Compulsivity, 25(4), 269-292. https://doi.org/10.1080/10720162.2019.1565848

Haidt. (2012). The Righteous Mind: Why Good People Are Divided by Politics and Religion. Knopf Doubleday Publishing Group.

Haidt, J., \& Graham, J. (2007). When Morality Opposes Justice: Conservatives Have Moral Intuitions that Liberals may not Recognize. Social Justice Research, 20(1), 98-116. https://doi.org/10.1007/s11211-007-0034-z

Haidt, J., \& Hersh, M. A. (2001). Sexual morality: The cultures and emotions of conservatives and liberals. Journal of Applied Social Psychology, 31(1), 191-221.

Haidt, J., \& Joseph, C. (2007). The moral mind: How five sets of innate intuitions guide the development of many culture-specific virtues, and perhaps even modules. The Innate Mind, 3, 367-391.

Haidt, J., Koller, S. H., \& Dias, M. G. (1993). Affect, culture, and morality, or is it wrong to eat your dog? Journal of Personality and Social Psychology, 65(4), 613. 
Helzer, E. G., \& Pizarro, D. A. (2011). Dirty Liberals! Reminders of Physical Cleanliness Influence Moral and Political Attitudes. Psychological Science, 22(4), 517-522.

Hill, S. E. (2007). “The Ooze Of Gluttony”: Attitudes Towards Food, Eating, And Excess In The Middle Ages. The Seven Deadly Sins, 57-70.

Hill, S. E. (2011). Eating to excess: The meaning of gluttony and the fat body in the ancient world. Praeger.

Hofmann, W., Meindl, P., Mooijman, M., \& Graham, J. (2018). Morality and self-control: How they are intertwined and where they differ. Current Directions in Psychological Science, 27(4), 286-291.

Horberg, E. J., Oveis, C., Keltner, D., \& Cohen, A. B. (2009). Disgust and the moralization of purity. Journal of Personality and Social Psychology, 97(6), 963-976. https://doi.org/10.1037/a0017423

Inbar, Y., \& Pizarro, D. (2021). How Disgust Affects Social Judgments. PsyArXiv. https://doi.org/10.31234/osf.io/axhvn

Inbar, Y., Pizarro, D. A., \& Bloom, P. (2012). Disgusting smells cause decreased liking of gay men. Emotion, 12(1), 23-27. https://doi.org/10.1037/a0023984

Inbar, Y., Pizarro, D. A., Knobe, J., \& Bloom, P. (2009). Disgust sensitivity predicts intuitive disapproval of gays. Emotion, 9(3), 435-439. https://doi.org/10.1037/a0015960

Johnson, D. J., Wortman, J., Cheung, F., Hein, M., Lucas, R. E., Donnellan, M. B., Ebersole, C. R., \& Narr, R. K. (2016). The Effects of Disgust on Moral Judgments: Testing Moderators. Social Psychological and Personality Science, 7(7), 640-647. https://doi.org/10.1177/1948550616654211

Jylkkä, J., Härkönen, J., \& Hyönä, J. (2021). Incidental disgust does not cause moral condemnation of neutral actions. Cognition and Emotion, 35(1), 96-109. https://doi.org/10.1080/02699931.2020.1810639 
Kayyal, M. H., Pochedly, J., McCarthy, A., \& Russell, J. A. (2015). On the limits of the relation of disgust to judgments of immorality. Frontiers in Psychology, 6. https://doi.org/10.3389/fpsyg.2015.00951

Knoch, D., Schneider, F., Schunk, D., Hohmann, M., \& Fehr, E. (2009). Disrupting the prefrontal cortex diminishes the human ability to build a good reputation. Proceedings of the National Academy of Sciences, 106(49), 20895-20899. https://doi.org/10.1073/pnas.0911619106

Landy, J. F., \& Goodwin, G. P. (2015). Does Incidental Disgust Amplify Moral Judgment? A Meta-Analytic Review of Experimental Evidence. Perspectives on Psychological Science, 10(4), 518-536. https://doi.org/10.1177/1745691615583128

Langlands, R. (2006). Sexual Morality in Ancient Rome. Cambridge University Press. https://doi.org/10.1017/CBO9780511482823

Le Goff, J. (1984). Le refus du plaisir in L'amour et la sexualité: Vol. Amour et Sexualité en Occident (Points Histoire, pp. 52-59).

Levine, D. N. (1965). Wax \& Gold: Tradition And Innovation In Ethiopian Culture. University of Chicago Press. https://ehrafworldcultures-yaleedu.proxy.library.upenn.edu/document?id=mp05-011

Levine, H. (1993). Temperance Cultures: Concern About Alcohol as a Problem in Nordic and English-speaking Cultures. In The Nature of Alcohol and Drug-Related Problems (New York: Oxford University Press, pp. 16-36).

Lie-Panis, J., \& André, J.-B. (2021). Cooperation as a signal of time preferences. PsyArXiv. https://doi.org/10.31234/osf.io/p6hc4

Lugo, L., Cooperman, A., Bell, J., O’Connell, E., \& Stencel, S. (2013). The World's Muslims: Religion, Politics and Society. POLITICS AND SOCIETY, 226. 
Manrique, H. M., Zeidler, H., Roberts, G., Barclay, P., Walker, M., Samu, F., Fariña, A., Bshary, R., \& Raihani, N. (2021). The psychological foundations of reputation-based cooperation. Philosophical Transactions of the Royal Society B: Biological Sciences, 376(1838), 20200287. https://doi.org/10.1098/rstb.2020.0287

Mernissi, F. (2011). Beyond the Veil: Male-female Dynamics in Modern Muslim Society. Saqi Books.

Merritt, A. C. (2013). The Interpersonal Costs of Indulgence. Stanford University.

Michalak, L., \& Trocki, K. (2006). Alcohol and Islam: An Overview. Contemporary Drug Problems, 33(4), 523-562. https://doi.org/10.1177/009145090603300401

Moffitt, T. E., Arseneault, L., Belsky, D., Dickson, N., Hancox, R. J., Harrington, H., Houts, R., Poulton, R., Roberts, B. W., Ross, S., Sears, M. R., Thomson, W. M., \& Caspi, A. (2011). A gradient of childhood self-control predicts health, wealth, and public safety. Proceedings of the National Academy of Sciences, 108(7), 2693-2698. https://doi.org/10.1073/pnas.1010076108

Mooijman, M., Meindl, P., Oyserman, D., Monterosso, J., Dehghani, M., Doris, J. M., \& Graham, J. (2018). Resisting temptation for the good of the group: Binding moral values and the moralization of self-control. Journal of Personality and Social Psychology, 115(3), 585-599. https://doi.org/10.1037/pspp0000149

Moon, J. W., Wongsomboon, V., \& Sevi, B. (2021). Beliefs about Men's Sexual Self-Control Predict Attitudes toward Women's Immodest Clothing and Public Breastfeeding [Preprint]. PsyArXiv. https://doi.org/10.31234/osf.io/67vh9

Mukhopadhyay, A., \& Yeung, C. (2010). Building character: Effects of lay theories of selfcontrol on the selection of products for children. 47(2), 240-250.

Najjar, L. Z., Young, C. M., Leasure, L., Henderson, C. E., \& Neighbors, C. (2016). Religious perceptions of alcohol consumption and drinking behaviours among 
religious and non-religious groups. Mental Health, Religion \& Culture, 19(9), 10281041.

Nettle, D., \& Saxe, R. (2021). 'If Men Were Angels, No Government Would Be Necessary’: The Intuitive Theory of Social Motivation and Preference for Authoritarian Leaders. Collabra: Psychology, 7(1), 28105. https://doi.org/10.1525/collabra.28105

Newhauser, R., \& Ridyard, S. J. (Eds.). (2012). Sin in medieval and early modern culture: The tradition of the seven deadly sins. The University of York / York Medieval Press.

Nichols, A., \& Maner, J. (2008). The Good-Subject Effect: Investigating Participant Demand Characteristics. The Journal of General Psychology, 135, 151-165. https://doi.org/10.3200/GENP.135.2.151-166

Nisbett, R., \& Wilson, T. (1977). The Halo Effect: Evidence for Unconscious Alteration of Judgments. Journal of Personality and Social Psychology, 35, 250-256. https://doi.org/10.1037/0022-3514.35.4.250

NYLAN, M. (2001). On the Politics of Pleasure. Asia Major, 14(1), 73-124.

Peetz, J., \& Kammrath, L. (2013). Folk understandings of self regulation in relationships: Recognizing the importance of self-regulatory ability for others, but not the self. Journal of Experimental Social Psychology, 49(4), 712-718. https://doi.org/10.1016/j.jesp.2013.02.007

Piazza, J., Landy, J. F., Chakroff, A., Young, L., \& Wasserman, E. (2018). What disgust does and does not do for moral cognition. The Moral Psychology of Disgust, 53-81.

Piazza, J., Sousa, P., Rottman, J., \& Syropoulos, S. (2019). Which Appraisals Are Foundational to Moral Judgment? Harm, Injustice, and Beyond. Social Psychological and Personality Science, 10(7), 903-913. https://doi.org/10.1177/1948550618801326 
Poushter, J. (2014). What's morally acceptable? It depends on where in the world you live. Pew Research Center. https://www.pewresearch.org/fact-tank/2014/04/15/whatsmorally-acceptable-it-depends-on-where-in-the-world-you-live/

Righetti, F., \& Finkenauer, C. (2011). If you are able to control yourself, I will trust you: The role of perceived self-control in interpersonal trust. Journal of Personality and Social Psychology, 100(5), 874-886. https://doi.org/10.1037/a0021827

Ringel, M. M., \& Ditto, P. H. (2019). The moralization of obesity. Social Science \& Medicine, 237, 112399. https://doi.org/10.1016/j.socscimed.2019.112399

Roberts, G. (2020). Honest signaling of cooperative intentions. Behavioral Ecology, 31(4), 922-932. https://doi.org/10.1093/beheco/araa035

Royzman, E., Atanasov, P., Landy, J. F., Parks, A., \& Gepty, A. (2014). CAD or MAD? Anger (not disgust) as the predominant response to pathogen-free violations of the divinity code. Emotion, 14(5), 892-907. https://doi.org/10.1037/a0036829

Royzman, E. B., Kim, K., \& Leeman, R. F. (2015). The curious tale of Julie and Mark: Unraveling the moral dumbfounding effect. Judgment and Decision Making, 10(4), 296.

Royzman, E. B., Leeman, R. F., \& Baron, J. (2009). Unsentimental ethics: Towards a content-specific account of the moral-conventional distinction. Cognition, 112(1), 159-174. https://doi.org/10.1016/j.cognition.2009.04.004

Rozin, P., Lowery, L., Imada, S., \& Haidt, J. (1999). The CAD Triad Hypothesis: A Mapping Between Three Moral Emotions (Contempt. Disgust) and Three Moral Codes (Community, Autonomy, Divinity), Journal of Personality and Social Psychology $76 / 4$ 
Ruddock, H. K., \& Hardman, C. A. (2017). Food Addiction Beliefs Amongst the Lay Public: What Are the Consequences for Eating Behaviour? Current Addiction Reports, 4(2), 110-115. https://doi.org/10.1007/s40429-017-0136-0

Saroglou, V., \& Craninx, M. (2021). Religious moral righteousness over care: A review and a meta-analysis. Current Opinion in Psychology, 40, 79-85. https://doi.org/10.1016/j.copsyc.2020.09.002

Saroglou, V., Delpierre, V., \& Dernelle, R. (2004). Values and religiosity: A meta-analysis of studies using Schwartz's model. Personality and Individual Differences, 37(4), 721734. https://doi.org/10.1016/j.paid.2003.10.005

Schein, C., \& Gray, K. (2018). The Theory of Dyadic Morality: Reinventing Moral Judgment by Redefining Harm. Personality and Social Psychology Review, 22(1), 32-70. https://doi.org/10.1177/1088868317698288

Schein, C., Ritter, R. S., \& Gray, K. (2016). Harm mediates the disgust-immorality link. Emotion, 16(6), 862-876. https://doi.org/10.1037/emo0000167

Schmitt, D. P. (2004). The Big Five related to risky sexual behaviour across 10 world regions: Differential personality associations of sexual promiscuity and relationship infidelity. European Journal of Personality, 18(4), 301-319. https://doi.org/10.1002/per.520

Sebastián-Enesco, C., \& Warneken, F. (2015). The shadow of the future: 5-Year-olds, but not 3-year-olds, adjust their sharing in anticipation of reciprocation. Journal of Experimental Child Psychology, 129, 40-54. https://doi.org/10.1016/j.jecp.2014.08.007

Seidman, S. (1990). The Power of Desire and the Danger of Pleasure: Victorian Sexuality Reconsidered. Journal of Social History, 24(1), 47-67. https://doi.org/10.1353/jsh/24.1.47 
Sjåstad, H. (2019). Short-sighted greed? Focusing on the future promotes reputation-based generosity. Judgment and Decision Making, 14(2), 199-213.

Stanford, P. K. (2018). The difference between ice cream and Nazis: Moral externalization and the evolution of human cooperation. Behavioral and Brain Sciences, 41, e95. https://doi.org/10.1017/S0140525X17001911

Sterckx, R. (Ed.). (2005). Of Tripod and Palate. Palgrave Macmillan US. https://doi.org/10.1057/9781403979278

Stevens, J. R., Cushman, F. A., \& Hauser, M. D. (2005). Evolving the Psychological Mechanisms for Cooperation. Annual Review of Ecology, Evolution, and Systematics, 36(1), 499-518. https://doi.org/10.1146/annurev.ecolsys.36.113004.083814

Stevens, J. R., \& Hauser, M. D. (2004). Why be nice? Psychological constraints on the evolution of cooperation. Trends in Cognitive Sciences, 8(2), 60-65. https://doi.org/10.1016/j.tics.2003.12.003

Sweeney, E. (2012). Aquinas on the Seven Deadly Sins: Tradition and Innovation. In R. G. N. S. J. Ridyard (Ed.), Sin in Medieval and Early Modern Culture: The Tradition of the Seven Deadly Sins. York Medieval Press/Boydell and Brewer.

Tangney, J. P., Baumeister, R. F., \& Boone, A. L. (2004). High self-control predicts good adjustment, less pathology, better grades, and interpersonal success. Journal of Personality. https://doi.org/10.1111/j.0022-3506.2004.00263.x

Tierney, W., Hardy, J., Ebersole, C. R., Viganola, D., Clemente, E. G., Gordon, M., Hoogeveen, S., Haaf, J., Dreber, A., Johannesson, M., Pfeiffer, T., Huang, J. L., Vaughn, L. A., DeMarree, K., Igou, E. R., Chapman, H., Gantman, A., Vanaman, M., Wylie, J., ... Uhlmann, E. L. (2021). A creative destruction approach to replication: Implicit work and sex morality across cultures. Journal of Experimental Social Psychology, 93, 104060. https://doi.org/10.1016/j.jesp.2020.104060 
Tingley, D., Yamamoto, T., Hirose, K., Keele, L., \& Imai, K. (2014). mediation: $R$ Package for Causal Mediation Analysis. Journal of Statistical Software, 59(5). https://doi.org/10.18637/jss.v059.i05

Tomasello, M. (2016). A natural history of human morality. Harvard University Press.

Vatuk, V. P., \& Vatuk, S. J. (1967). Chatorpan: A Culturally Defined Form of Addiction in North India. International Journal of the Addictions, 2(1), 103-113. https://doi.org/10.3109/10826086709074414

Vazsonyi, A. T., Mikuška, J., \& Kelley, E. L. (2017). It's time: A meta-analysis on the selfcontrol-deviance link. Journal of Criminal Justice, 48, 48-63. https://doi.org/10.1016/j.jcrimjus.2016.10.001

Vonasch, A. J., Clark, C. J., Lau, S., Vohs, K. D., \& Baumeister, R. F. (2017). Ordinary people associate addiction with loss of free will. Addictive Behaviors Reports, 5, 5666. https://doi.org/10.1016/j.abrep.2017.01.002

Vonasch, A. J., \& Sjåstad, H. (2021). Future-Orientation (as Trait and State) Promotes Reputation-Protective Choice in Moral Dilemmas. Social Psychological and Personality Science, 12(3), 383-391. https://doi.org/10.1177/1948550619899257

Wagemans, F. M. A., Brandt, M. J., \& Zeelenberg, M. (2018). Disgust sensitivity is primarily associated with purity-based moral judgments. Emotion, 18(2), 277-289. https://doi.org/10.1037/emo0000359

Weeden, J., \& Kurzban, R. (2013). What predicts religiosity? A multinational analysis of reproductive and cooperative morals. Evolution and Human Behavior, 34(6), 440445. https://doi.org/10.1016/j.evolhumbehav.2013.08.006

Weeden, J., \& Kurzban, R. (2016). The Hidden Agenda of the Political Mind: How SelfInterest Shapes Our Opinions and Why We Won't Admit It. Princeton University Press. 
